\title{
A Química no Cérebro
}

Raquel B. Dias ${ }^{1,2}$

\begin{abstract}
A transmissão de informação entre neurónios assenta na libertação de mediadores químicos - os neurotransmissores. É agora revista a contribuição de um químico orgânico para o estabelecimento do glutamato como principal neurotransmissor excitatório no cérebro.
\end{abstract}

Foi em 1791 que Luigi Galvani nos deu a conhecer a natureza eléctrica do impulso nervoso na junção neuro-muscular da rã, ao publicar o seu trabalho magistral, De viribus electricitatis in motu musculari commentarius [1]. Ferozmente contestada por Alessandro Volta [2], a sua teoria do Galvanismo, segundo a qual a "electricidade animal" dos tecidos biológicos Ihes permitiria responder a estímulos externos, fez-se repercutir à escala global, tendo inclusive inspirado Mary Shelley a escrever "Frankenstein; or, The Modern Prometheus", em 1817. De tal forma se enraizou na comunidade científica o conceito de bio-electricidade, que viria apenas a ser já no século $X X$ demonstrada a ocorrência de transmissão nervosa por meio de mediadores químicos (Loewi, em 1921 [3]).

Foi assim identificado o primeiro neurotransmissor - a acetilcolina, a que Loewi chamou Vagusstoff. Como a própria designação sugere, os neurotransmissores são substâncias químicas endógenas que veiculam, amplificam e modulam sinais entre um neurónio e uma outra célula do corpo - outro neurónio ou uma fibra muscular, por exemplo. De facto, desempenham funções de cuja complexidade dificilmente se poderia suspeitar pela análise da sua estrutura química. Basta pensar que o glutamato, um simples aminoácido, é o principal neurotransmissor excitatório do cérebro.
O estudo da transmissão excitatória mediada pelo glutamato no sistema nervoso central iniciou-se na década de 1950, sensivelmente ao mesmo tempo em que a Neuroquímica dava os seus primeiros passos enquanto disciplina científica de pleno direito. É neste contexto que assume particular relevância o trabalho de Jeffrey Watkins.

Logo após acabar o seu doutoramento em Química Orgânica, foi-lhe atribuída a tarefa de testar os efeitos de diferentes substâncias químicas, previamente identificadas como constituintes do tecido cerebral, por forma a seleccionar candidatos adequados a neurotransmissores. Em conjunto com David Curtis e John Phillis, observou pela primeira vez o efeito excitatório, despolarizante, que o L-glutamato exercia em neurónios da medula espinal de gato [4]. Mas antes de avançarem com a hipótese de que o glutamato seria efectivamente um neurotransmissor, descobriram que ao usar outros aminoácidos desprotonados a $\mathrm{pH}$ fisiológico, como o D-glutamato ou o aspartato, obtinham um efeito bastante comparável, de potência quase equivalente, ao observado com o L-glutamato. E como poderia o glutamato ser um neurotransmissor, se não possuísse receptores específicos através dos quais pudesse propagar sinais entre neurónios adjacentes?

Felizmente, Watkins lembrou-se de testar diferentes análogos sintéticos do glutamato e tentar correlacionar as suas estruturas com os respectivos efeitos elicitados em tecido cerebral.

Uma vez que as acções dos enantiómeros levógiro e dextrógiro do glutamato eram bastante equivalentes, Watkins optou por estudar análogos com substituintes mais volumosos, onde uma possível estereoselectividade pelo potencial receptor de glutamato se tornasse evidente. Uma destas substâncias, o N-metil-D-aspartato (MNDA) acabou por revelar um efeito excitatório consideravelmente superior ao do próprio L-glutamato, comprovando que teria realmente de existir um receptor para todos estes aminoácidos e seus derivados, cujo domínio de ligação apresentasse estereoselectividade responsável por efeitos de potência variável de acordo com o análogo usado.<smiles>N[C@@H](CCC(=O)O)C(=O)O</smiles><smiles>CNC(CC(=O)O)(C(=O)O)[N+](=O)[O-]</smiles> 
Foi assim proposto um modelo para o receptor de glutamato, em que os grupos carregados e polares do glutamato interagiriam com três domínios de ligação no receptor [5], desencadeando uma alteração conformacional responsável por abrir poros na membrana neuronal através dos quais o fluxo de iões sódio, de acordo com o gradiente, gerasse entrada de cargas positivas para a célula e a sua consequente despolarização. Sabe-se hoje que este domínio de ligação ao glutamato é formado por dois segmentos de polipéptidos do receptor (denominados S1 e S2), contendo os terminais amino de quatro hélices $\alpha$, gerando um potencial electroestático consideravelmente negativo. Muito embora a carga do glutamato seja também negativa, esta destabilização é compensada pelo estabelecimento de pontes de hidrogénio, pontes salinas e interacções electrostáticas entre ambos [6]. Assim, a afinidade e especificidade de ligação de diferentes ligandos ao receptor de glutamato é definida por este tipo de interacções, que causam inclusive diferentes graus de fecho dos domínios de ligação, o que explica que alguns análogos de glutamato possam causar uma activação excessiva destes receptores, com consequências tóxicas para os neurónios.

De facto, para além do desenvolvimento de outros análogos sintéticos como o a-amino-3-hidroxil-5-metil-4-isoxazol-propionato (AMPA), que viria a revelar-se fundamental à elaboração de um sistema de classificação dos diferentes tipos de receptores para o glutamato de acordo com a sua afinidade para diferentes ligandos, foram ainda isolados potentes análogos do glutamato a partir de algas (kainato,
Digenia simplex) e plantas (quisqualato, Quisqualis spp). Da mesma forma e na sequência de um surto de intoxicações por ingestão de bivalves contaminados, na ilha Prince Edward, Canadá, em 1987, descobriu-se que uma toxina produzida por micro-algas, o ácido domóico, é capaz de activar os receptores para o glutamato com uma potência 30 a 100 vezes superior à do próprio ligando endógeno. Ao acumular-se nos bivalves que consomem estas algas, por sua vez consumidos por animais como humanos ou gaivotas, o ácido domóico leva a um aumento de função desreguladora de vias glutamatérgicas e, consequentemente, a sintomas de desorientação, amnésia, tremores, volatilidade emocional e mesmo danos neurológicos irreversíveis. Se considerarmos a estrutura química do ácido domóico, vemos que, à semelhança do kainato, possui um anel pirrolidínico, mas neste caso, com um grupo funcional de maiores dimensões, que funciona como uma cunha que se interpõe na estrutura definida pelo domínio de ligação ao glutamato do receptor. bandos de pardelas negras enlouquecidas. Apesar da causa desta loucura colectiva ter ficado na altura por descobrir, o caso terá inspirado Daphne du Maurier a escrever a novela em que se baseou o famoso filme de $\mathrm{Hi}$ tchcock, "os Pássaros", de 1963.

\section{REFERÊNCIAS}

[1] L. Galvani, "De viribus electricitatis in motu musculari commentarius", Bon. Sci. Art. Inst. Acad. Comm. 7 (1971) 363-418.

[2] A. Volta, "Le opere di Alessandro Volta" (edizione nazionale, 2 vols), 1918, Hoepli, Milano.

[3] O. Loewi, "Über humorale Übertragbarkeit der Herznerven-wirkung", Pflügers Archiv. 189 (1921) 239-242.

[4] D. R. Curtis, J. W. Phillis, J. C. Watkins, "The chemical excitation of spinal neurones by certain acidic amino acids", $J$. Physiol. 150 (1960) 656-682.

[5] D. R. Curtis, J. C. Watkins, "The excitation and depression of spinal neurones by structurally related amino acids", J. Neurochem. 6 (1960) 117-141.

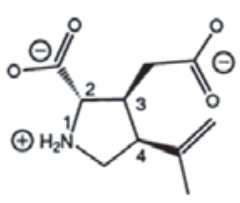

Kainato

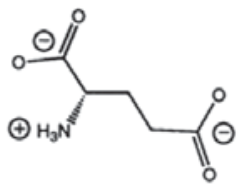

Glutamato

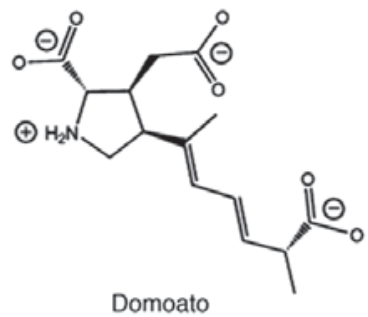

Domoato

Figura 2 Estrutura de alguns agonistas de receptores para o glutamato (Adaptado de Armstrong et al. [6])

Curiosamente, os efeitos da intoxicação por ácido domóico já eram conhecidos em aves marinhas desde 1961, altura em que a cidade costeira de Capitola foi alvo de "ataques" por
[6] N. Armstrong, Y. Sun, G.-Q. Chen, E. Gouaux, "Structure of a glutamate receptor ligand-binding core in complex with kainate", Nature 395 (1998) 913$-917$.

\section{Actualidade Científica}

Baterias recarregáveis de lítio: DESAFIOS

Tem sido notícia o esforço de várias marcas automóveis para lançarem carros eléctricos no mercado, enquadrado na procura de alternativas ao uso de combustíveis fósseis. Embora já haja automóveis híbridos em circulação, procura-se investir em automóveis inteiramente eléctricos. Em particular, foi recentemente divulgada a intenção de uma marca em construir uma fábrica de baterias em Portugal. A bateria é, nesta altura, o elemento que limita a autonomia dos veículos automóveis, sendo por isso uma área onde se desenvolve um grande esfor- ço de investigação. Como as baterias estão associadas à mobilidade, são também muito importantes para os telemóveis, computadores portáteis e outros equipamentos electrónicos.

Para este tipo de aplicação, o objectivo é conseguir baterias recarregáveis (também designadas por baterias se- 
cundárias e idealmente capazes de sofrer um número "infinito" de ciclos de carga e descarga sem perda de performance), seguras, baratas, com elevada capacidade e com voltagem elevada. São de facto muitas características que se pretendem optimizar simultaneamente.

Uma pilha é constituída por um ânodo e um cátodo, estando estes dois eléctrodos separados por um electrólito que, permitindo o fluxo iónico entre os eléctrodos, não deve, no entanto, transportar electrões. No ânodo, o pólo negativo, ocorre uma oxidação, sendo os electrões transportados através de um circuito externo (onde realizam trabalho eléctrico e podem assim impulsionar o carro) até ao cátodo, o pólo positivo, onde ocorre uma redução que consome esses electrões. O papel do electrólito, nesta descrição simples, é fechar o circuito eléctrico, compensando a deslocação de electrões com a deslocação de iões (ver Figura 1). A força electromotriz da pilha é determinada pelos potenciais de redução dos eléctrodos. Este é o funcionamento das baterias (que combinam várias pilhas em série) de chumbo há muito usadas nos automóveis. Contudo, por possuírem um electrólito líquido (com ácido sulfúrico) e serem muito pesadas, nunca foram equacionadas como solução para o carro eléctrico.

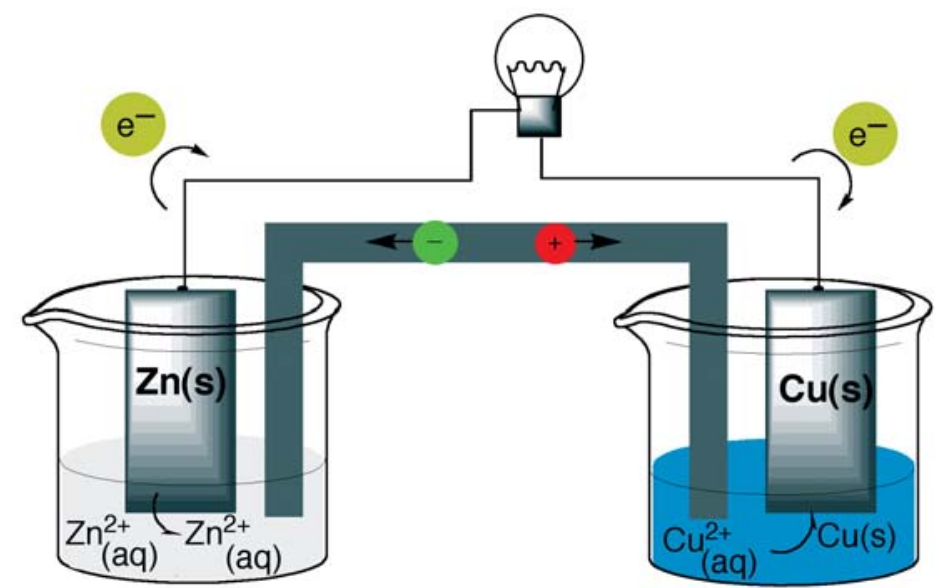

Figura 1 Pilha de Daniell. Neste caso, como não se pode usar um electrólito comum aos dois eléctrodos, usa-se uma ponte salina (gel com sal iónico dissolvido) que assegura a condutividade iónica entre os dois eléctrodos

O lítio, por possuir um potencial de redução muito negativo (sendo fácil de oxidar, o que o torna muito reactivo, não podendo por exemplo contactar com água por reagir violentamente com esta), pode originar pilhas com elevada força electromotriz, tendo sido testado em pilhas que usam electrólitos não aquosos. Contudo, a aplicação mais segura deste elemento em baterias envolve idealmente apenas o ião lítio, não devendo criar-se condições, por razões de segurança, para a formação de lítio metálico. Dado tratar-se do catião metálico mais pequeno, permite criar electrólitos em que este apresenta elevadas mobilidades. Note-se que a força electromotriz de uma pilha é determinada pelos potenciais dos eléctrodos mas a tensão que ela efectivamente cria, quando em funcionamento, e a energia que ela pode fornecer dependem da cinética dos processos de transferência electrónica e, mais importante, da mobilidade dos iões no electrólito. Estes têm que compensar a carga transportada pelos electrões que se movem muito rapidamente no circuito exterior à pilha. E a mobilidade dos iões é fortemente dependente do seu tamanho (de facto há um transporte de massa).

As pilhas recarregáveis de lítio são baseadas na movimentação do ião lítio entre dois eléctrodos, sendo a reacção principal a de intercalação/desintercalação do lítio nos dois eléctrodos. Em termos simples, tudo se passa como se, no processo de descarga, o ião lítio saísse de um eléctrodo, o ânodo, e fosse intercalar-se no cátodo. A movimentação deste ião é acompanhada de um fluxo de electrões, no circuito

exterior, no mesmo sentido. Note-se que no electrólito ideal para esta piIha só os iões lítio devem ser móveis. A título de exemplo, consideremos a pilha de ião lítio mais simples, constituída por grafite intercalada com lítio, funcionando como ânodo, e um óxido de cobalto com lítio intercalado, como cátodo, separados por um electrólito não aquoso:

No processo de descarga, os iões lítio são libertados da grafite para o electrólito e, no cátodo, os iões lítio do electrólito são intercalados no óxido de cobalto. A reacção de oxidação é

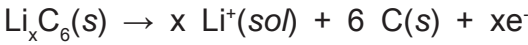
(ânodo) (1)

Nesta reacção o número de oxidação do lítio não se altera, e é o carbono que é formalmente oxidado.

A reacção de redução é

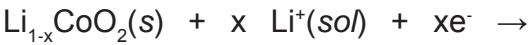
$\mathrm{LiCOO}_{2}(\mathrm{~s})$ (cátodo) (2)

Nesta última reacção o número de oxidação formal do lítio não se altera, e é o cobalto que é reduzido.

A reacção global é
$\mathrm{Li}_{\mathrm{x}} \mathrm{C}_{6}(\mathrm{~s})+\mathrm{Li}_{1-\mathrm{x}} \mathrm{CoO}_{2}$
$6 \mathrm{C}(\mathrm{s})+\mathrm{LiCoO}_{2}(\mathrm{~s})$
(s) $\rightarrow$

No processo de carga desta pilha, aplica-se uma tensão de sinal oposto à gerada por ela, ligando o pólo negativo de uma fonte ao eléctrodo de $\mathrm{Li}_{\mathrm{x}} \mathrm{C}_{6}$, que funciona agora como cátodo, o que obriga à ocorrência do processo inverso de (1), e o pólo positivo da fonte ao eléctrodo de $\mathrm{LiCoO}_{2}(s)$, promovendo o processo inverso de (2). A durabilidade da pilha deriva da completa reversibilidade destes processos de intercalação/desintercalação e da inexistência de reacções secundárias (por esta razão há pilhas comerciais que não devem ser recarregadas porque no processo de carga podem ocorrer reacções que libertem gases que provocam a explosão das pilhas).Estas pilhas de ião lítio são actualmente as mais usadas em computadores portáteis, telemóveis e as que estão a ser desenvolvidas para o fabrico do carro eléctrico.

Face à actualidade e interesse desta tecnologia, foi recentemente publicado um artigo de revisão (Chemistry of Materials 22 (2010) 587-603)) em que se discutem os desafios actuais, tendo em vista a aplicação das baterias recarregáveis de ião lítio em veículos eléctricos. São abordados os desafios dos vários componentes, conforme se mostra na Figura 2. 


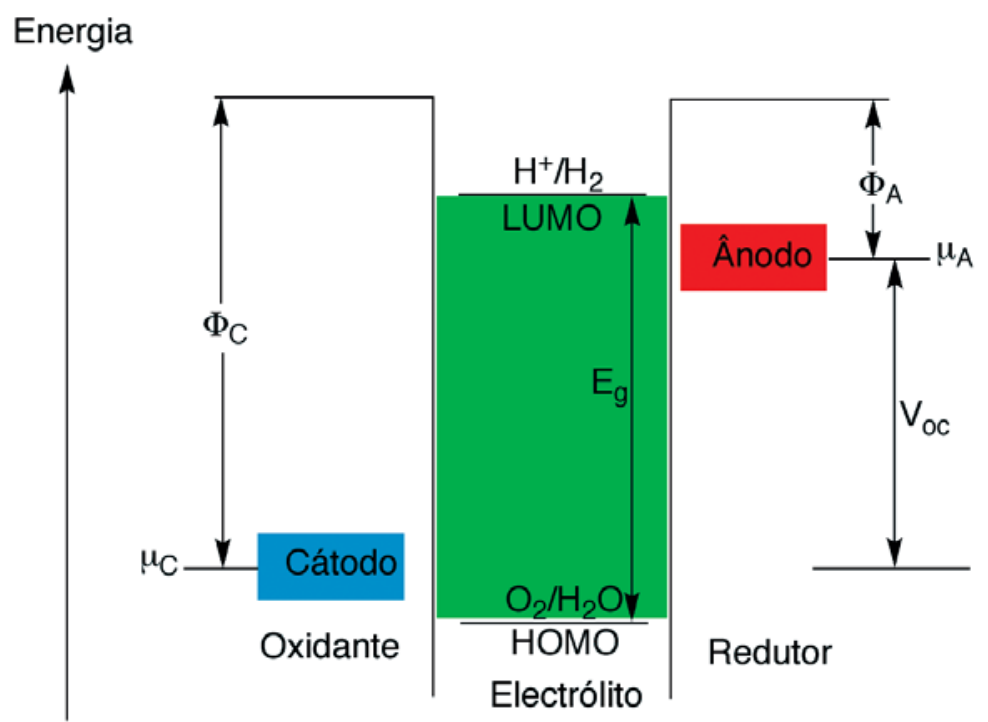

Figura 2 Esquema de uma pilha em circuito aberto, em que se especificam as funções de trabalho dos eléctrodos $\left(\Phi_{A}\right.$ e $\left.\Phi_{c}\right)$ e os potenciais electroquímicos $\left(\mu_{A}\right.$ e $\left.\mu_{c}\right)$ ou energias de Fermi $\varepsilon_{p}$ e a força electromotriz, $V_{\text {oc }}$.(Adaptado de Chemistry of Materials 22 (2010) 587-603))

No esquema da Figura 2 considera-se um electrólito aquoso, sendo evidenciada a janela de estabilidade electroquímica, $\mathrm{E}_{\mathrm{g}}$, da água. Se o ânodo tiver um potencial electroquímico acima do nível $\mathrm{H}^{+} / \mathrm{H}_{2}$ (ou, mais genericamente, da LUMO - orbital molecular não ocupada de menor energia - de um outro electrólito), provoca a redução do electrólito $\left(\mathrm{H}^{+}+\mathrm{e}^{-} \rightarrow 1 / 2 \mathrm{H}_{2}\right.$ ) (a menos que seja criada uma barreira de passivação entre eles que impeça a transferência electrónica). Se o cátodo tiver um potencial electroquímico abaixo do potencial do par $\mathrm{O}_{2} / \mathrm{H}_{2} \mathrm{O}$ (ou abaixo da HOMO - orbital molecular ocupada de mais alta energia - do electrólito), provocará a oxidação do electrólito $\left(2 \mathrm{H}_{2} \mathrm{O} \rightarrow \mathrm{O}_{2}+4 \mathrm{H}^{+}+4 \mathrm{e}^{-}\right)$(a menos que seja criada uma barreira de passivação entre eles que impeça a transferência electrónica). Ou seja, na ausência de camadas de passivação, o electrólito será estável desde que os potenciais electroquímicos de ânodo e cátodo estejam dentro da janela de estabilidade electroquímica do electrólito. No caso das pilhas de ião lítio, a água não pode ser usada por não satisfazer este requisito de estabilidade. A densidade de energia de uma pilha é dada pelo produto da tensão em circuito aberto (força electromotriz, $V_{\text {oc }}$ ) pela capacidade de transferência de carga reversível por unidade de massa. Os desafios que se colocam ao desenvolvimento de uma bateria de lítio recarregável para o mercado dos veículos automóveis são: a identificação de materiais baratos e ambientalmente benignos para os componentes das pilhas, i.e., (1) um electrólito não aquoso com elevada condutividade por ião $\mathrm{Li}^{+}$na gama de temperaturas entre $-40{ }^{\circ} \mathrm{C}$ e $60^{\circ} \mathrm{C}$; (2) ânodo e (3) cátodo com valores de $\mu_{A}$ e $\mu_{C}$ adequados à janela de estabilidade do electrólito e permitindo ambos os eléctrodos ciclos de carga/descarga rápidos com elevada capacidade reversível.

Eléctrodos - Os materiais de eléctrodo são optimizados em relação aos valores de $\mu_{\mathrm{A}}$ e $\mu_{\mathrm{C}}$, tendo em conta o posicionamento energético da LUMO e HOMO do electrólito, tendo, além disso, que ser quimicamente estáveis quando em contacto com o electrólito. Os eléctrodos práticos desenvolvidos até hoje são essencialmente constituídos por uma estrutura hospedeira na/da qual os iões lítio são inseridos/ extraídos. Como materiais hospedeiros para inserção de lítio têm sido estudados a grafite ou carvão desordenado e outros elementos (como o silício); óxidos e sulfuretos de metais de transição $\left(\mathrm{Li}_{\mathrm{x}} \mathrm{TiS}_{2}\right.$ e $\mathrm{Li}_{\mathrm{x}} \mathrm{CoO}_{2}$, com estruturas em camadas, espinelas $\left[\mathrm{Ti}_{2}\right] \mathrm{S}_{4}$, e $\mathrm{Li}_{\mathrm{x}} \mathrm{CoPO}_{4}$ ) e compostos em que ocorrem reacções de deslocamento de lítio (substituição de um elemento de um composto ou liga, como foi demonstrado com a substituição do ferro em $\mathrm{Fe}_{3} \mathrm{O}_{4}$ por inserção de lítio). Dos materiais até agora estudados do lado do ânodo, será difícil encontrar um que permita maior capacidade que o carbono embora este tenha uma baixa velocidade de carga; do lado do cátodo falta ainda encontrar um material que permita maximizar a voltagem e capacidade das células.

Electrólitos - Além de possuir uma grande janela de estabilidade electroquímica, Eg, o electrólito deve ainda satisfazer outros requisitos, como a manutenção de uma boa qualidade de interface com os eléctrodos (acomodando as variações de volume que acompanham a inserção/desinserção de lítio), uma elevada condutividade iónica, apenas por $\mathrm{Li}^{+}$, e desprezável condutividade electrónica, e estabilidade química na gama de temperaturas de $-40{ }^{\circ} \mathrm{C}$ a $60{ }^{\circ} \mathrm{C}$ e por contacto com os eléctrodos. Deve, além disso, ser seguro (de preferência não deve ser inflamável nem explosivo caso ocorra um curto-circuito) e ter baixa toxicidade e baixo custo. Entre os electrólitos estudados, estão os líquidos orgânicos, em especial os que se baseiam em carbonatos (carbonato de propileno e carbonato etilmetílico, por exemplo); líquidos iónicos (como os sais de imidazole que, contudo, têm uma baixa estabilidade electroquímica e nos quais a mobilidade do $\mathrm{Li}^{+}$é pequena); electrólitos líquidos inorgânicos; electrólitos poliméricos sólidos, como por exemplo os baseados em misturas de poli(óxido de etileno) e sais de lítio $\left(\mathrm{LiPF}_{6}\right.$ ou $\mathrm{LiAsF}_{6}$ ), mas que possuem uma moderada mobilidade do ião $\mathrm{Li}^{+}$; electrólitos sólidos inorgânicos, que possuem uma janela de estabilidade electroquímica larga, mas que foram excluídos das aplicações em grande escala destas baterias por terem problemas com a instabilidade da interface com os eléctrodos; e os sistemas electrólitos mistos, que combinam líquidos orgânicos, líquidos iónicos, electrólitos poliméricos e/ou electrólitos sólidos inorgânicos. Apesar da enorme quantidade de estudos já efectuados não parece ter sido ainda encontrado o electrólito ideal, que cumpra todos os requisitos acima referidos. Em conclusão, embora existam já no mercado baterias recarregáveis de ião lítio e sejam estas as eleitas para os veículos eléctricos, e embora haja já uma vasta quantidade de materiais para os seus componentes, não foram ainda encontrados os que cumprem todos requisitos identificados como necessários para optimizar estas baterias.

Jorge Morgado 